\title{
Transanal Minimally Invasive Surgery
}

\author{
Teresa deBeche-Adams, MD $^{1}$ George Nassif, $\mathrm{DO}^{1}$ \\ ${ }^{1}$ Center for Colon and Rectal Surgery, Florida Hospital, Orlando, \\ Florida \\ Address for correspondence Teresa deBeche-Adams, MD, Center for \\ Colon and Rectal Surgery, Florida Hospital, 258 S Chickasaw Trl, \#201, \\ Orlando, FL 32825 (e-mail: debeche.adams@gmail.com).
}

Clin Colon Rectal Surg 2015;28:176-180.

\begin{abstract}
Keywords

- transanal

- rectal cancer

- local excision

- minimally invasive

- TAMIS

Transanal minimally invasive surgery (TAMIS) was first described in 2010 as a crossover between single-incision laparoscopic surgery and transanal endoscopic microsurgery (TEM) to allow access to the proximal and mid-rectum for resection of benign and earlystage malignant rectal lesions. The TAMIS technique can also be used for noncurative intent surgery of more advanced lesions in patients who are not candidates for radical surgery. Proper workup and staging should be done before surgical decision-making. In addition to the TAMIS port, instrumentation and set up include readily available equipment found in most operating suites. TAMIS has proven its usefulness in a wide range of applications outside of local excision, including repair of rectourethral fistula, removal of rectal foreign body, control of rectal hemorrhage, and as an adjunct in total mesorectal excision for rectal cancer. TAMIS is an easily accessible, technically feasible, and cost-effective alternative to TEM.
\end{abstract}

As minimally invasive procedures continue to evolve, many boundaries are being pushed to establish less invasive techniques with minimal surgical trauma, equivalent clinical results, and improved patient satisfaction. Transanal endoscopic microsurgery (TEM), introduced over 30 years ago by Dr. Gerhard Buess, provides the criteria for this. ${ }^{1-6}$ It has proven to be superior over standard transanal excision for local excision of rectal masses, most notably because of its ability to perform high-quality resections. ${ }^{7,8}$ The benefit is likely because of the quality optics, specialized instruments, and specialized insufflation system. Despite its great fit into our minimally invasive society, TEM has met many roadblocks to adoption, mostly attributable to its steep learning curve and expensive equipment. ${ }^{9-11}$ Because of this, lesions of the mid and upper rectum remain somewhat of an enigma for colorectal surgeons. Patients are referred to specialized centers performing TEM or are subjected to more radical surgery, such as a low anterior resection (LAR) or abdominoperineal resection (APR).

Born out of the need for a practical alternative to TEM that was both affordable and technically feasible, transanal minimally invasive surgery (TAMIS) is a novel technique developed as a hybrid between TEM and single-site laparoscopy for resection of rectal lesions. Originally described in 2010 by Atallah et al, ${ }^{12}$ TAMIS was designed on a platform that was readily available in most hospitals, bringing access for more proximal rectal lesions to any advanced laparoscopist with rectal surgery familiarity.

\section{Preoperative Considerations}

The workup and decision-making to perform a local resection using TAMIS mirrors that of TEM and standard transanal resection. ${ }^{13}$ We know from published TEM data that the advanced approach allows for a more intact, nonfragmented specimen (100 vs. $63 \%$ ), more likely results in negative resection margins (98 vs. $78 \%$ ), and has a lower recurrence rate ( 8 vs. $24 \%$ ) than standard transanal excision. ${ }^{8}$ This is echoed in the TAMIS data with a $4 \%$ fragmentation rate, $6 \%$ microscopic margin positivity, and a $2 \%$ recurrence rate as published by Albert et al. ${ }^{14}$ Though there is ample data comparing TEM to standard transanal excision and to radical intra-abdominal approaches, there is a paucity of publications comparing TEM and TAMIS. An ex vivo study by Rimonda et al ${ }^{15}$ showed comparable results for achieving a good dissection by surgeons not trained in
Issue Theme Evolving and Emerging Technologies in Colon and Rectal Surgery; Guest Editors: Thomas E. Cataldo, MD, FACS, FASCRS; Deborah Nagle, MD, FACS, FASCRS
Copyright $\odot 2015$ by Thieme Medical Publishers, Inc., 333 Seventh Avenue, New York, NY 10001, USA.

Tel: +1(212) 584-4662.
DOI http://dx.doi.org/ 10.1055/s-0035-1555008. ISSN 1531-0043. 
transanal techniques using both TEM and TAMIS equipment.

Once the lesion has been identified, a colonoscopy should be performed to rule out any synchronous lesions and to biopsy the rectal mass. It should be localized with physical examination, including digital rectal examination and rigid proctoscopy. Documentation should be made of the height and positional orientation of the lesion. Careful attention should be paid to whether the tumor is soft or firm and mobile or fixed. Further workup for accurate staging should be performed. In our institution, we favor both rectal magnetic resonance imaging and endorectal ultrasound (EUS) in combination. Computed tomography of the chest, abdomen, and pelvis are also ordered to rule out metastatic disease.

\section{Patient Selection}

The indications for TAMIS are similar to TEM and standard transanal resection. ${ }^{16}$ For patients with benign rectal neoplasms or well-selected T1 cancers with histologically favorable features where the risk of nodal metastasis is low, ${ }^{17}$ a TAMIS resection should be considered. The discussion with the patients would be widely centered on preservation of rectal function with the understanding that they still need close follow-up postoperatively. For patients with questionable T1 versus T2 lesions with no evidence of nodal metastasis, a TAMIS resection can serve as an "excisional biopsy," guiding further treatment with the final pathology report. These patients should be counseled preoperatively that they would have a curative-intent surgery if the pathology returns as a T1 lesion, but that they may still need a formal oncologic resection in the form of an LAR if the pathology returns as a T2 lesion.

Patients with more advanced lesions (T3) can be considered for TAMIS resection when they are medically unfit to have a more radical surgery. Those patients found to have nodal disease or distant metastases should be evaluated by a multidisciplinary cancer board and considered for preoperative chemotherapy and radiation. The indications for TAMIS can also be broadened to include local excision of cT0 lesions in patients with locally advanced rectal cancer after neoadjuvant therapy for the purpose of confirming mural cPR (ypT0). ${ }^{18-20}$ This can be considered a valid option, as the risk of occult node positivity for ypT0 lesions is predictably low, at 3 to $6 \%{ }^{21-23}$

\section{Surgical Preparation}

All patients should have orders following standard Surgical Care Improvement Project (SCIP) protocols for colon surgery, including perioperative antibiotics, $\beta$ blockers, and deep venous thrombosis prophylaxis. The decision for preoperative bowel preparation can be left up to the surgeon's preference. A flexible sigmoidoscopy preparation is more than adequate for visualization in most patients. Some may prefer to have their patients perform a full mechanical bowel preparation.

An advantage of TAMIS is that all patients are positioned in the lithotomy position regardless of the lesion location. This facilitates quicker set up times in the operating room and is preferred by most anesthesiologists because of better airway control and a lower risk of perioperative complications. Candy cane or Allen stirrups can be used based on their availability. If there is any question that intra-abdominal access may be needed, Allen stirrups are preferred so that the legs may be lowered for the abdominal portion of the procedure. Patients should be low on the table to facilitate transanal access with their legs high enough to prevent encroachment on the surgeon's working space. A slight bit of Trendelenburg position can be added if needed. A video monitor just between the patient's legs over the abdomen seems to be the most ergonomic position for the primary viewpoint. Patients can then be prepped and draped in the normal fashion.

\section{Set Up and Equipment}

Some of the advantages of TAMIS over TEM include rapid setup time, 360 versus 220 degrees of visibility within the rectal lumen, the ability to universally adapt to any existing laparoscopic instrument, and the ease of lithotomy positioning within the operating theater. ${ }^{12,24-31}$ The initial description of the procedure reported a set-up time as rapid as 1.9 minutes. ${ }^{12}$ This greatly reduces the total operative time when compared with TEM. The cost of the single-use ports used for TAMIS is nearly equivalent to the cost of the disposable $\mathrm{CO}_{2}$ tubing required for each TEM case. ${ }^{12,25}$ TAMIS may also result in less short-term anal sphincter dysfunction than TEM, as has been shown using the rigid 40-mm TEM scope. $^{12,32,33}$

There are currently two Food and Drug Administrationapproved devices for transanal access with the TAMIS procedure-the SILS Port (Covidien, Mansfield, MA) and the GelPOINT Path (Applied Medical, Rancho Santa Margarita, CA). Both easily seat transanally and allow insufflation for pneumorectum through a designated channel. The remainder of the equipment is standard laparoscopic instrumentation found in the operating room. Pneumorectum is achieved using a typical laparoscopic tower with $\mathrm{CO}_{2}$ for insufflation. Initial pressure settings should be between 15 and $18 \mathrm{~mm} \mathrm{Hg}$ and can be increased if there is difficulty in maintaining distention for visualization. We strongly recommend general anesthesia with muscle paralysis to avoid collapse of the rectal wall which often occurs with diaphragmatic excursion.

Local excision using the da Vinci robotic system (Intuitive Surgical, Sunnyvale, CA) has been described and overcomes the limitations of straight laparoscopic instruments with wristed maneuverability. ${ }^{34-36}$ This may be particularly useful with more complex and intricate surgery, such as the repair of a rectourethral fistula described later. Positioning and set up can be quite cumbersome with this technique and specialized training is a prerequisite for using the system. This may add cost and time to the procedure, contradicting the original intentions of TAMIS, but with further investigation it may be a less invasive alternative to previously radical procedures.

Hemorrhoidectomy and laparoscopic cholecystectomy trays include almost all the necessary instruments for the procedure. A 30- or 45-degree angled laparoscope provides 
better maneuverability and visualization during dissection than 0-degree scopes. Bariatric length laparoscopes can also be used to prevent instrument clashing. Alternatively, a colonoscope $^{37}$ or flexible tipped scopes have also been described for visualization. Maryland graspers, or the like, can be used for retraction.

Dissection can easily be performed with monopolar cautery. This can be connected to a standard suction irrigator to serve a dual function. More advanced bipolar devices can also be used but will add expense to the procedure. These are less applicable for a submucosal dissection but can be used nicely in a full-thickness resection.

Closure of the defect can be accomplished with simple laparoscopic suturing using standard needle drivers or with more advanced laparoscopic closure devices. These devices may be more expensive but may hasten the operating period, as closure of the defect is one of the more time-consuming portions of the procedure. Laparoscopic suture clips can be used to decrease the closure time as well.

\section{Technical Considerations}

Resection of lesions should follow standard principles used in transanal resection or TEM. Benign adenomas can be resected in the submucosal plane with pathologically negative margins. These defects do not necessarily need to be closed as they are not full-thickness defects. For malignant lesions, a $1 \mathrm{~cm}$ margin should be marked out around the entire mass before beginning a full-thickness resection. This will ensure maintaining a negative and adequate margin during the dissection. Care must be taken to remain perpendicular to the tumor so as not to compromise the deep margin. A pyramidal-type dissection can be accomplished on posterior tumors to allow harvesting of several lymph nodes in the area for pathologic evaluation. Importantly, the $\mathrm{CO}_{2}$ insufflation provides a natural "pneumo-dissection" thereby augmenting the ease and clarity of the planes during local excision using TAMIS.

It is a standard procedure at our institution to close all defects. This provides good practice so that if an intraperitoneal entry occurs, it can be easily handled. Intraluminal knottying can be accomplished with the use of a knot-pusher or laparoscopic suture clips. Defects are closed transversely so as not to narrow the lumen of the rectum and can be done in a running stitch or with multiple figure-of-eight stitches. For patients with previous radiation, an interrupted technique is preferred given the high incidence of wound dehiscence. If intraperitoneal entry does take place, a Gastrografin enema should be done before discharge to ensure that there is no leak.

If a lesion is very distal (i.e., at or just above the dentate line), the distal margin can be incised using standard transanal retractors and electrocautery. Before the start of the lateral portion of the dissection, the TAMIS port can be inserted to be used for the remainder of the dissection. This allows for better visualization of the proximal extent of the tumor and less fragmentation of the specimen. A single stitch can then be placed on the proximal edge of the defect in its midportion and used to pull down and reap- proximate to the distal edge using a standard transanal approach.

\section{Postoperative Care}

Patients undergoing TAMIS resection are typically discharged on the same day of surgery. Depending on comorbidities, the option to admit for 23-hour observation with discharge on the first postoperative day is equally feasible. There are no dietary restrictions. Patients can be transitioned to oral antibiotics with anaerobic and gram negative coverage for a period of 7 days if it is the surgeon's preference.

Standard follow-up is at 2 and 6 weeks. Rigid proctoscopy is performed as part of the clinical examination to assess healing. Patients with malignant lesions who underwent a satisfactory TAMIS excision are followed according to National Comprehensive Cancer Network guidelines depending on final pathology. For patients with excised specimens that reveal more advanced disease or histologically unfavorable features, standard oncologic resection is recommended.

\section{Expanding Applications}

Utilization of the TAMIS platform continues to expand, mostly because it provides easy accessibility to the rectum and the pelvis that allows it to be used for various other applications. TAMIS has now been successfully performed with a variety of ports, ${ }^{12,25,38}$ including other commercially available singlesite ports and even a customized glove port. ${ }^{39,40}$ With improved transanal visibility and exposure, TAMIS has been described for repair of rectourethral fistula, ligation of distal rectal hemorrhage, and removal of rectal foreign body. ${ }^{41}$ Still other investigators have used TAMIS to control postoperative anastomotic bleeding and to provide access for suture closure of an anastomotic leak.

The same TAMIS platform has been used for transanal NOTES surgery, ${ }^{42}$ a technique originally performed with TEM. $^{43,44}$ The proctectomy is completed in a "reverse" approach. This overcomes the difficulty of the narrow pelvis especially in male patients and tackles the trouble of the distal margin. Because the dissection is started from below, the distal margin is never in question. It may also provide better dissection of the circumferential margin of the distal mesorectum. 45

\section{Discussion}

Since its initial description in 2010, TAMIS has gained considerable momentum with multiple series and published reports showing it to be a feasible, low-cost alternative to TEM. ${ }^{24-31}$ TAMIS should not be considered an alternative to standard oncologic resection for locally advanced tumors. Currently, only patients with benign lesions or histologically favorable, early-stage malignancy (uTis or uT1 uN0 M0 cancer) are considered candidates for TAMIS as curative-intent surgery because of the scarcity of oncological data. More advanced lesions require standard resection (APR vs. LAR) except in patients who are not medically fit to undergo major 
surgery. Patients with stage IV disease or locally advanced lesions are not candidates for TAMIS unless the objective is palliation. While TAMIS has been successfully performed in the lower, mid, and upper rectum, it is perhaps best suited for mid and lower rectal lesions, providing a less morbid alternative to anterior resection or APR in well-selected patients. The versatility of TAMIS as a means to perform more complex and intricate surgery including repair of rectovaginal/urethral fistula, ligation of distal gastrointestinal hemorrhage, removal of foreign body, and total mesorectal excision (TME) in the difficult pelvis makes TAMIS an exciting future platform for pelvic surgery. The most exciting application for TAMIS may be the "bottom up" TME dissection for the difficult pelvis.

\section{References}

1 Buess G, Theiss R, Günther M, Hutterer F, Pichlmaier H. Transanal endoscopic microsurgery [in German]. Leber Magen Darm 1985; 15(6):271-279

2 Buess G, Kipfmüller K, Hack D, Grüssner R, Heintz A, Junginger T. Technique of transanal endoscopic microsurgery. Surg Endosc 1988;2(2):71-75

3 Buess G, Mentges B, Manncke K, Starlinger M, Becker HD. Technique and results of transanal endoscopic microsurgery in early rectal cancer. Am J Surg 1992;163(1):63-69, discussion 69-70

4 Saclarides TJ, Smith L, Ko ST, Orkin B, Buess G. Transanal endoscopic microsurgery. Dis Colon Rectum 1992;35(12):1183-1191

5 Lev-Chelouche D, Margel D, Goldman G, Rabau MJ. Transanal endoscopic microsurgery: experience with 75 rectal neoplasms. Dis Colon Rectum 2000;43(5):662-667, discussion 667-668

6 Cataldo PA. Transanal endoscopic microsurgery. Surg Clin North Am 2006;86(4):915-925

7 de Graaf EJ, Burger JW, van Ijsseldijk AL, Tetteroo GW, Dawson I, Hop WC. Transanal endoscopic microsurgery is superior to transanal excision of rectal adenomas. Colorectal Dis 2011;13(7): 762-767

8 Moore JS, Cataldo PA, Osler T, Hyman NH. Transanal endoscopic microsurgery is more effective than traditional transanal excision for resection of rectal masses. Dis Colon Rectum 2008;51(7): 1026-1030, discussion 1030-1031

9 Maslekar S, Pillinger SH, Sharma A, Taylor A, Monson JR. Cost analysis of transanal endoscopic microsurgery for rectal tumours. Colorectal Dis 2007;9(3):229-234

10 Koebrugge B, Bosscha K, Ernst MF. Transanal endoscopic microsurgery for local excision of rectal lesions: is there a learning curve? Dig Surg 2009;26(5):372-377

11 Christoforidis D, Cho HM, Dixon MR, Mellgren AF, Madoff RD, Finne CO. Transanal endoscopic microsurgery versus conventional transanal excision for patients with early rectal cancer. Ann Surg 2009;249(5):776-782

12 Atallah S, Albert M, Larach S. Transanal minimally invasive surgery: a giant leap forward. Surg Endosc 2010;24(9):2200-2205

13 Cataldo PA. Local excision of rectal cancer. In: Beck DE, et al, eds. The ASCRS Textbook of Colon and Rectal Surgery. 2nd ed. New York: Springer Verlag; 2011:731-741

14 Albert MR, Atallah SB, deBeche-Adams TC, Izfar S, Larach SW. Transanal minimally invasive surgery (TAMIS) for local excision of benign neoplasms and early-stage rectal cancer: efficacy and outcomes in the first 50 patients. Dis Colon Rectum 2013;56(3): 301-307

15 Rimonda R, Arezzo A, Arolfo S, Salvai A, Morino M. TransAnal Minimally Invasive Surgery (TAMIS) with SILS $^{\text {TM }}$ port versus
Transanal Endoscopic Microsurgery (TEM): a comparative experimental study. Surg Endosc 2013;27(10):3762-3768

16 Qi Y, Stoddard D, Monson JR. Indications and techniques of transanal endoscopic microsurgery (TEMS). J Gastrointest Surg 2011;15(8):1306-1308

17 Nascimbeni R, Burgart LJ, Nivatvongs S, Larson DR. Risk of lymph node metastasis in T1 carcinoma of the colon and rectum. Dis Colon Rectum 2002;45(2):200-206

18 Garcia-Aguilar J, Shi Q, Thomas CR Jr, et al. A phase II trial of neoadjuvant chemoradiation and local excision for T2N0 rectal cancer: preliminary results of the ACOSOG Z6041 trial. Ann Surg Oncol 2012;19(2):384-391

19 Kundel Y, Brenner R, Purim O, et al. Is local excision after complete pathological response to neoadjuvant chemoradiation for rectal cancer an acceptable treatment option? Dis Colon Rectum 2010; 53(12):1624-1631

$20 \mathrm{Kim}$ CJ, Yeatman TJ, Coppola D, et al. Local excision of T2 and T3 rectal cancers after downstaging chemoradiation. Ann Surg 2001; 234(3):352-358, discussion 358-359

21 Bedrosian I, Rodriguez-Bigas MA, Feig B, et al. Predicting the nodenegative mesorectum after preoperative chemoradiation for locally advanced rectal carcinoma. J Gastrointest Surg 2004;8(1): 56-62, discussion 62-63

22 Bujko K, Nowacki MP, Nasierowska-Guttmejer A, et al; Polish Colorectal Study Group. Prediction of mesorectal nodal metastases after chemoradiation for rectal cancer: results of a randomised trial: implication for subsequent local excision. Radiother Oncol 2005;76(3):234-240

23 Yeo SG, Kim DY, Kim TH, et al. Pathologic complete response of primary tumor following preoperative chemoradiotherapy for locally advanced rectal cancer: long-term outcomes and prognostic significance of pathologic nodal status (KROG 09-01). Ann Surg 2010;252(6):998-1004

24 Lim SB, Seo SI, Lee JL, et al. Feasibility of transanal minimally invasive surgery for mid-rectal lesions. Surg Endosc 2012;26(11): 3127-3132

25 Barendse RM, Doornebosch PG, Bemelman WA, Fockens P, Dekker E, de Graaf EJ. Transanal employment of single access ports is feasible for rectal surgery. Ann Surg 2012;256(6):1030-1033

26 Matz J, Matz A. Use of a SILS port in transanal endoscopic microsurgery in the setting of a community hospital. J Laparoendosc Adv Surg Tech A 2012;22(1):93-96

27 Lorenz C, Nimmesgern T, Back M, Langwieler TE. Transanal single port microsurgery (TSPM) as a modified technique of transanal endoscopic microsurgery (TEM). Surg Innov 2010;17(2):160-163

28 Ragupathi M, Haas EM. Transanal endoscopic video-assisted excision: application of single-port access. JSLS 2011;15(1): 53-58

29 Khoo RE. Transanal excision of a rectal adenoma using singleaccess laparoscopic port. Dis Colon Rectum 2010;53(7): 1078-1079

30 Smith RA, Anaya DA, Albo D, Artinyan A. A stepwise approach to transanal endoscopic microsurgery for rectal cancer using a single-incision laparoscopic port. Ann Surg Oncol 2012;19(9): 2859

31 Watts ES, Peacock O, Gupta A, Speake WJ, Lund JN. Anyone for TAMIS? Tech Coloproctol 2013;17(2):253-255

32 Kennedy ML, Lubowski DZ, King DW. Transanal endoscopic microsurgery excision: is anorectal function compromised? Dis Colon Rectum 2002;45(5):601-604

33 Wang HS, Lin JK, Yang SH, Jiang JK, Chen WS, Lin TC. Prospective study of the functional results of transanal endoscopic microsurgery. Hepatogastroenterology 2003;50(53):1376-1380

34 Atallah SB, Albert MR, deBeche-Adams TH, Larach SW. Robotic TransAnal Minimally Invasive Surgery in a cadaveric model. Tech Coloproctol 2011;15(4):461-464 
35 Hompes R, Rauh SM, Ris F, Tuynman JB, Mortensen NJ. Robotic transanal minimally invasive surgery for local excision of rectal neoplasms. Br J Surg 2014;101(5):578-581

36 Atallah S, Parra-Davila E, DeBeche-Adams T, Albert M, Larach S. Excision of a rectal neoplasm using robotic transanal surgery (RTS): a description of the technique. Tech Coloproctol 2012; 16(5):389-392

37 McLemore EC, Coker A, Jacobsen G, Talamini MA, Horgan S. eTAMIS: endoscopic visualization for transanal minimally invasive surgery. Surg Endosc 2013;27(5):1842-1845

38 Barendse RM, Verlaan T, Bemelman WA, et al. Transanal single port surgery: selecting a suitable access port in a porcine model. Surg Innov 2012;19(3):323-326

39 Hompes R, Ris F, Cunningham C, Mortensen NJ, Cahill RA. Transanal glove port is a safe and cost-effective alternative for transanal endoscopic microsurgery. Br J Surg 2012;99(10):1429-1435

40 Alessandro C, Daniela M, Michele M, et al. Glove port technique for transanal endoscopic microsurgery. Int J Surg Oncol 2012; 2012(12):383025
41 Atallah S, Albert M, Debeche-Adams T, Larach S. Transanal minimally invasive surgery (TAMIS): applications beyond local excision. Tech Coloproctol 2013;17(2):239-243

42 Gaujoux S, Bretagnol F, Au J, Ferron M, Panis Y. Single port access proctectomy with total mesorectal excision and intersphincteric resection with a primary transanal approach. Colorectal Dis 2011; 13(9):e305-e307

43 Sylla P. Current experience and future directions of completely NOTES colorectal resection. World J Gastrointest Surg 2010;2(6): 193-198

44 Sylla P, Rattner DW, Delgado S, Lacy AM. NOTES transanal rectal cancer resection using transanal endoscopic microsurgery and laparoscopic assistance. Surg Endosc 2010;24(5): 1205-1210

45 de Lacy AM, Rattner DW, Adelsdorfer C, et al. Transanal natural orifice transluminal endoscopic surgery (NOTES) rectal resection: “down-to-up" total mesorectal excision (TME)-shortterm outcomes in the first 20 cases. Surg Endosc 2013;27(9): 3165-3172 